\section{EFFECTS OF CLOTHING AND FUEL SHORTAGE ON HEALTH*}

\author{
By SIR Leonard Hill, F.R.S.
}

$\mathrm{H}$

AIR, feathers, fur and clothes protect the body from loss of heat, not by the quality of solid substance but by the air entangled in the meshes of these. Air is a bad heat conductor; warmed up to skin temperature and kept stationary, it acts as an insulator, preventing heat loss.

If the thermal conductivity of air be taken as unity that of wool fibre is 6 , of water at least 240 . The heat capacity of water is more than 3,000 times that of air, hence the great cooling power of cold water. A given volume of fur consists of about 2 per cent solid and 98 per cent air. A rabbit with skin shaved and varnished had its heat loss increased by nearly $1 \frac{1}{2}$ times in a room at ordinary temperature.

Darwin described natives of Tierra del Fuego-the woman with babe at her breast, naked in the falling sleet, the man with an otter-skin the size of a handkerchief, which he shifted to the side struck by the wind. Sleeping on the ground like hares these natives had to commit infanticide, so hardy were they, to keep the population down to the food supply. Native Australians kept dogs to warm themselves at night, stripping bark off a tree to protect their naked bodies from wind. Eskimo dressed in furs withstand howling blizzards and temperatures as low as $70^{\circ} \mathrm{F}$. of frost, and will crouch with their spears over the holes patiently waiting for seals to come up to breathe, and so stay even for three days. In their igloos, built of snow blocks over ice, which is much warmer than frozen land, they use blubber-lamps, and are so warm with these and their own body heat, that they discard all clothing while inside. Roman Catholic priests, born in Paris, have acclimatized themselves to live as Eskimos protected by fur garments. One such priest lived in a hole in the ground, far colder than an igloo. The northern Chinese, who endure five months of rigorously cold weather, use little fuel, but attain comparative comfort by wearing a wadded gown with long sleeves, and wadded trousers bound round the ankle. Cotton waste is used as wadding. Contrast these garments with the thin underclothing, short skirts, silk stockings and thin shoes of our womenfolk. Here is the way to save fuel-if people wear suitable clothing, houses and factories need be far less heated. The Chinese do not have an open fireplace with most of the heat going up the chimney, but a stove, with a long metal pipe as flue, which, while traversing the room, gives up its heat.

To save fuel women's thin and flimsy garments can be amplified by overalls, trousers and tunics, with such undergarments as are available. Shawls, overcoats and mackintoshes can be worn indoors for sedentary occupations, and their protective effect can be amplified, if needed, by a hot bottle to the feet and a rug over the knees. People can thus keep warm without artificial heat, as they do in the back seat of a motor-car. The factories would then have to be artificially heated only just enough to keep the hands warm for skilled work.

For sedentary occupations an ordinary citizen secures an atmosphere under his clothes of about $91^{\circ} \mathrm{F}$.; only about one fifth of his skin surface is exposed to the air. Naked he finds a room at $80^{\circ} \mathrm{F}$. pleasant, one at $60^{\circ} \mathrm{F}$. cold. Those who habitually

- Substance of a Chadwick Public Lecture delivered on October 6. go with little clothing and are most exposed to the open air show the greatest immunity to what are termed 'colds'-respiratory affections which are really caused by infection in stuffy, artificially heated rooms. Leaving aside the question of fuel-saving, modern girls in their scant attire get the advantage of sun and air, as does the boy scout with shorts, bare knees and a shirt open at the neck. Babies, for fear of cold, are often overclad, and head sweating and evaporation from the lungs are then sometimes the only means left for getting rid of body heat. The children in an open-air sanatorium, clad in one garment, sit up in bed and play, indifferent to open windows. Out of doors they enjoy exposure nude to sun and air, but the exposure must not be overdone. The children must be able to assimulate enough wellchosen food to produce the body heat production required.

Exposure to cold makes the lamp of life burn brightly. A baby is born with great powers to withstand changes of climatic environment. Well fed, and given some exposure to open air and sun, naked when the weather is good, allowed plenty of kicking and crawling, with no prolonged confinement when awake in cradle and perambulator, with long sleeps out of doors, and light clothing, babies grow up virile with strong muscles and firm bones. While in winter a man may carry a tenth of his weight in his clothes, a dog carries only 2 per cent of its weight in its fur. A woman in modern dress carries less than half as much as a man, but have in consequence suffered no more from 'colds', pneumonia or rheumatism, and their death-rate has not been put up. The secondary schools have turned out fine, healthy and athletic girls and the women have worked wonders in the munitions factories.

Clothing should not be so heavy as to interfere with the taking of vigorous exercise. The athlete wears scanty clothing because his efforts may increase his heat production by five times or more.

It is a mistake except in very cold weather to put on an overcoat when going out to walk. The overcoat is useful when sitting indoors so as to allow a window open on a cool day. It is only the old, the underfed and ill and feeble who require very warm clothing. It should be kept in mind that those who are paralysed, anæsthetized or in a state of shock have lost their power of heat regulation and may easily be over-heated by hot bottles and too much clothing. The difference between the winter and summer pelts of the horse and cow show the small amount of extra clothing needed to face the open air in winter. Thick woollens and furs are needed not by citizens but by arctic travellers, airmen and soldiers in freezing trenches.

Clothes require to be made so as to be easily adjusted to changes of climate, in place of being fashioned to satisfy vanity. They should be as light as possible, allow free evaporation, become to the least degree wet with sweat and not cling to the skin when wet. The cellular structure produced by weaving, whether of wool, cotton, linen or silk, secures conditions which by entanglement of air gives warmth, pliability and evaporative power. Smooth, closely woven and glazed materials, as in a mackintosh or oilskin, give protection from wind and water. Wool has an elastic fibre which when worn keeps the garment off the skin, and prevents it clinging when wet. A fine woven linen or cotton is cooler than flannel because less air is entangled within the meshes. Made equally cellular in strueture, linen or cotton 
garments are as warm as flannel, but they cling when wet.

The question of wetting and clinging and of wearing and washing properties have to be taken into account. By taking off an outer garment, and by free ventilation, work can be carried out in factories in warm weather and without excessive call on the workers sweat mechanism, which is the emergency method of keeping cool.

Fashion and custom should not prevent people taking off outer garments when feeling too warm. Employees should then be encouraged to work in their shirt sleeves, or bare to the waist. Heat loss from the body is then made easier by ventilation and free evaporation of sweat and by radiation of the skin to cooler surroundings. The evolution of the warm-blooded animal took place when animals warmed up by the sun succeeded by greater activity so induced, and came to evolve mechanisms for lessening heat loss in the shade by increasing heat production. Tropical lizards expand their pigment cells in their skin, and, absorbing sun rays, are warmed up to about $100^{\circ} \mathrm{F}$. and then become very active. By open mouth and rapid breathing they evaporate enough water to prevent over-heating. At night they become cold and inert. Such lizards warmed by hot water pipes at the Zoo died in the winter. Given radiant heat on my suggestion, they eat and thrive. At body temperature black skin emits radiant heat rays just as much as white skin, but white skin reflects sun rays about double as much as black, which also absorbs much more. In the black and white furred animals exposed to the sun the black patches are much warmer than the white; so too, in the sun the dark hair of the scalp is much warmer than the white skin, but custorn prevents consciousness of this difference. The sun's rays absorbed by the pigment of the skin increase transpiration from the capillaries and excite sweating and so cooling by evaporation. The black skin of a Negro when glistening with sweat reflects sun rays. Owing to protective pigment his skin can be thin and the blood vessels near to the surface; so the Negro loses heat easily from shaded parts of his body. The horny layer of the skin absorbs the short, active ultra-violet rays, and its thickening through exposure to these protects from sunburn. The pigment produced in the white skin by exposure to the sun protects the deeper parts of the skin from overheating.

Convention keeps children clothed in the tropics when they should wear only a loin-cloth, tan in the sun, be in and out of water and live open-air lives. Indoor conditions in the tropics make white women fade and age quickly. The white man can acclimatize himself to work in tropical heat when not overclothed and overfed. The conditions which favour heat-stroke are tight clothing and hot ground, high air humidity, little wind and crowding. The limits of heat regulation in still air are wet bulb temperatures of $90^{\circ} \mathrm{F}$. and $93^{\circ} \mathrm{F}$. in air moving at two miles an hour ; but work is then very inefficient. It is then most important to secure proper cooling of the body for workers by suitable clothing and ventilation. The heat loss from the body of a man engaged in ordinary physical work is required to be about three times that at rest, to counteract the greater body heat production.

The absorption of heat from the sun or a furnace may be much greater than the ordinary rate of heat loss, particularly in the case of a man in a black or dark garment. The conditions liable to give heatstroke are given by soldiers marching in full uniform, in close column in the sun on a calm day. Open order, stripping off of clothes, adequate water to drink, frequent rest, and a light diet are the means of prevention. White garments and helmets, and tents, reflect most sunlight, and the garments need to be open and flapping, so that ventilation is free. Shorts open at the knees, shirts open and short in the arms, and low cut and open in the neck are needed for hot climates. Aluminium foil can be used as a lining for tents to reflect sun-rays. Black or dark garments are worn in cold climates to absorb heat rays.

The cooling power of wind is enormous when the temperature is low. To resist this flying or aretic clothing consists of an outer layer of windproof material-strong, light, waterproof cloth will dowith inner layers of soft, fluffy woollens, entangling plenty of air. The garments join and even overlap, so that no wind enters at the neck, wrist, waist or ankle: a tunic with hood in one piece, gloves pulling up well over ouffs, and confined by straps, trousers coming well over tunic and confined by a belt, long boots made of supple hide coming well over trouser legs and strapped there, with soft woollen socks inside. A great trouble to arctic travellers is the moisture taken up by their sleeping-bags, which freezes by day and has to be thawed by night. Boots are best taken into the sleeping-bag to prevent them freezing. Wolverine is the fur used by Eskimos for head-cover because it does not take up the moisture breathed out.

Misty, damp atmosphere feels chilly owing to the hygroscopic properties of clothes and consequent dampness, with increased loss of body heat by evapora. tion of this moisture, while there is absence of radiant heat. Radiant heat from the sun and bright sky and warm ground or wall, make a great difference to comfort.

When bone dry, flannel will take up about 40 per cent of its weight of water, dry cotton or silk about half as much as wool ; the physical process of the absorption of water by dry materials raises their temperature. For example, three layers of wool wrapped round the bulb of a thermometer were made quite dry in a drying-chamber. The thermometer rose $10^{\circ} \mathrm{F}$. above the room temperature when it was suspended in the room owing to moisture absorbed from the air. Hence the warm feeling when well-dried clothes are put on. A woven cellular material takes up a great deal of water when wet, thus the clothing of a soldier may take up 8-9 lb. of water. To evaporate this amount would take up all the day's heat production of a sedentary worker. Woollens, owing to their elastic fibres, stick least to the skin when wet, and air still entangled in the meshes gives some protection against heat loss. Flannel is made up of 90 per cent air by volume and 2 per cent solid; smooth materials contain about 59 per cent of air. Starching and glazing make a garm nt almost airless, but impermeable to wind. Thus the smooth lining of an overcoat halves its permeability by wind.

While tropical clothing has a thickness of about $2 \mathrm{~mm}$., winter clothing may be $12 \mathrm{~mm}$. thick. The heat-retaining eificiency of clothing materials can be evaluated by means of the katathermometer. This, like the skin, is very sensitive to the cooling effect of wind. The ordinary thermometer gives the average temperature of the surroundings and is not affected by air movement. A room is comfortable when the 'kata' cooling power is 5-6. With the 'kata' clothed 
in a thick woollen glove the cooling power is about half what it is with the naked 'kata'. Where the so-clothed 'kata' gave readings of 3-5 and the naked 'kata' 6-10 on sunny days one can sit out in comfort in ordinary clothes. When in very cold weather the clothed 'kata' gave a cooling power of about 20, and the naked 'kata' about double as much, two overcoats, thick gloves and a muffler were needed, and even then one had to shelter from the wind to keep warm. If a rubber glove is pulled tight over the bulb of the 'kata' it gives almost no protection, but put on Ioose with fluffy wool underneath the protection is very great. When gloves of knitted wool, cotton, etc., are compared on the 'kata' it is evident that the nature of the fibres makes little difference. It is the air stationary in the meshes which protects. Three knitted garments put on the 'kata' bring down the cooling power to about one third of that of the naked 'kata'. If the outermost garment be wet the protection is lessened only a little, as the cooling by evaporation from this coat is small. If a single, wet, thin, knitted glove clings to the 'kata' the rate of cooling is very greatly increased owing to evaporation. The 'kata' then becomes a measure of cooling power by convection, radiation and evaporation.

The cooling power of a wet 'kata' placed between the shirt and the skin is about trebled when a table fan is directed to blow on the body. The effect of such a fan in cooling the skin by convection and evaporation of sweat is thus made evident. The 'kata' does not actually give the cooling power exerted on the body, because it is a small bulb with a big surface in proportion to the bulk and surface of the large human body. The 'kata' cooling powers for comfort are then determined empirically. The cooling power exerted by water on the 'kata' is fourteen times that of air at the same temperature. Stirring the water makes the rate of cooling much greater. If a thick woollen glove be loosely put on and covered with a thin rubber glove, and this tied on to the stem so that no water can enter, the two coats protect the 'kata' from cooling in cold water very greatly, for example, they make it one seventh of that of the naked 'kata'. The protection becomes much less when the inner woollen glove is wet, but is still considerable. The clothes are then a protection against heat loss when one is immersed in water owing to the air entangled in the meshes, and the retention of water therein which becomes warmed by the body.

Swimming naked in the cold sea puts up the heat production of an ordinary man seven or eight times. Channel swimmers are protected by a thick layer of subcutaneous fat, which acts as an insulator, and their skin is well greased so that water cannot soak. into it and increase its conductivity. Their heat production is very great owing to the powerful exercise as well as the cooling effect of water. They use up, therefore, some pounds of body fat and make this up afterwards. The heat loss of a naked man in air of $40^{\circ} \mathrm{F}$. and a wind of $61 \mathrm{ft}$. a second was found to be twice as great as when clothed. Fxposed in boats or on rafts people want warm clothing and water or windproof outer garments to keep themselves from dying of cold. Such garments and enough water to drink are the two main essentials, as people when kept warm can live many days without food.

Dr. Argyll Campbell and I made observations on the rate of heat loss from the body of a subject exposed to wind and splashing of waves, either naked or in light clothing, or in such clothing plus a onepiece waterproof suit. This was made by Sir Robert
Davis, of Messrs. Siebe Gorman, Ltd. The protection afforded by this suit was great, reducing the heat loss by one half. I directed the attention of the Minister of Transport to these observations, with the result that the Ministry designed a two-piece suit with a hood, all made of thin, light, oilskin material. The dress packs up in the hood, and this is carried by the merchant seamen just as a gas-mask is carried. More than 200,000 of these dresses have been issued, and the use of these contributes to the saving of life. The suit is coloured bright yellow, a colour easily seen from an aeroplane.

\section{NATIONAL FLOUR AND BREAD SECOND REPORT}

From the Scientific Adviser's Division, Ministry of Food

CAMPLES of National flour and bread are being $D$ examined as a routine. The first report ${ }^{1}$ covering 303 samples, of which 300 were received before 85 per cent flour became compulsory (March 23, 1942), showed that the mean values of fibre and $B_{1}$ were 0.70 per cent and 1.05 I.U./gm. respectively. The present report is a summary of the results obtained on 322 samples milled since the compulsory date together with a comparison of the quality of the flour before and after that date; it also summarizes the quality of 459 samples of bread.

Fibre and $B_{1}$. Table I shows the different levels of fibre and $B_{1}$ over the whole 322 samples :

\begin{tabular}{|c|c|c|c|}
\hline \multicolumn{2}{|c|}{ Fibre } & \multicolumn{2}{|c|}{ Vitamin $B_{1}$} \\
\hline $\begin{array}{c}\text { Value } \\
\%\end{array}$ & $\%$ of samples & $\begin{array}{c}\text { Value } \\
\%\end{array}$ & $\%$ of samples \\
\hline $\begin{array}{r}<0.4 \\
0.5 \\
0.6 \\
0.7 \\
0.8 \\
0.9\end{array}$ & $\begin{array}{r}8 \cdot 7 \\
13 \cdot 7 \\
29 \cdot 8 \\
50 \cdot 6 \\
70 \cdot 8 \\
85 \cdot 1\end{array}$ & $\begin{array}{r}1.10 \\
1.00 \\
0.90\end{array}$ & $\begin{array}{l}46 \cdot 6 \\
80 \cdot 7 \\
93 \cdot 5\end{array}$ \\
\hline
\end{tabular}

Since 85 per cent flour was made compulsory in Great Britain, millers have on occasions been allowed to admix a small amount of Canadian G.R. flour. In the period under review the average dilution in the samples received was 8.7 per cent. This would not affect the $B_{1}$ value, since the added G.R. flour is fortified to nearly the same level as National flour, but it would tend to reduce the fibre content; at a figure in the region of 0.7 per cent this reduction would be slightly less than 0.05 per cent. To compensate for this all the experimentally determined values of fibre have been increased by $0 \cdot 05$, although this correction, as an overall figure, is too great.

Riboflavin. Six flours taken at random from those having a fibre content of 0.7 per cent were examined for riboflavin ${ }^{2}$, with the results shown in the second column of Table 2.

\begin{tabular}{|c|c|c|c|}
\hline Sample & $\begin{array}{c}\text { Riboflavin } \\
v / \text { gm. }\end{array}$ & $\begin{array}{c}\mathbf{B}_{1} \\
\text { I.U./gm. }\end{array}$ & $\begin{array}{c}\text { Germ content } \\
\text { (approx.) }\end{array}$ \\
\hline & 1.7 & & 1.00 \\
1 & 1.9 & 1.10 & 1.0 \\
2 & 1.7 & 1.15 & 2.0 \\
3 & 1.7 & 1.20 & 1.0 \\
4 & 1.3 & 1.00 & 1.8 \\
5 & 1.7 & 1.15 & 1.2 \\
6 & 1.7 & 1.10 & 1.0 \\
Average & & \\
\hline
\end{tabular}

